\title{
Imagen y credibilidad de Estados Unidos en Europa: Cobertura de la guerra de Irak en la televisión europea
}

\author{
Teresa La Porte (Universidad de Navarra) \\ Recibido: 12/12/08 \\ Aprobado: 14/01/09
}

\begin{abstract}
RESUMEN: En Irak es tan decisiva la guerra como la discusión política. La polémica en torno a la legitimidad de la preemptive war y el poder de Estados Unidos para establecer su particular orden internacional, se desarrolla al mismo tiempo que la acción bélica. En esta situación, la imagen transmitida a través de los medios de comunicación, particularmente la TV, determina la credibilidad de Estados Unidos en Europa y explica el interés por analizar el contenido de los principales informativos.
\end{abstract}

Palabras clave: Antiamericanismo - comunicación política internacional diplomacia pública - poder blando - análisis de contenido en TV.

Image and credibility of the U.S. in Europe. Irak war coverage in
European TV

SUMMARY: In Iraq, political discussion is as relevant as the war itself. The controversy on the legitimacy of the "pre-emptive war" and the power of the United States to set out its specific World order marches in parallel to the military conflict. In this situation, the United States image reflected in the media, particularly on TV, is decisive to determine American credibility in Europe, and justifies interest in analyzing news content.

Key words: Antiamericanism - international political communication - public diplomacy - soft power - TV news content analysis. 


\section{Introducción: El debate político en torno a la guerra de Irak}

$\mathrm{L}$ a guerra de Irak pasará a la historia como uno de los acontecimientos decisivos para entender la seguridad internacional del siglo XXI. Si los atentados del 11 de setiembre del 2001 en Nueva York y Washington definieron el nuevo modelo de conflicto, la guerra de Irak define el debate sobre el orden internacional que comenzó en la década anterior.

En Irak es tan decisiva la guerra como la discusión política. El gran tema que prevalece sobre el desarrollo de la contienda es la polémica en torno a qué normas deben garantizar la seguridad mundial y cuál la autoridad que vele por su cumplimiento; o dicho de otro modo, la legitimidad de la preemptive war y el poder de Estados Unidos. Enfocado de este modo, el protagonista del conflicto de Irak sería la Administración Bush y no la tiranía de Sadam Hussein, por cuanto es Estados Unidos el que precipita la controversia al pronunciarse a favor de una política internacional no consensuada. ${ }^{1}$ Esta es la razón de que fuera tan relevante la posición que cada Estado adoptó con respecto a la visión norteamericana: una postura favorable a Washington reflejaba el acuerdo con el uso de la fuerza para prevenir acciones terroristas decididas en virtud del principio de defensa propia y, por tanto, al margen de la ONU, mientras que una postura crítica mostraría una preferencia por los cauces multilaterales y diplomáticos de resolución de conflictos.

La propuesta norteamericana de cooperación en la intervención armada en Irak generó una profunda división entre los gobiernos de la Unión Europea: mientras Reino Unido, España, Portugal e Italia la respaldaron, Francia y Alemania se opusieron a cualquier tipo de colaboración. Una división similar se produjo en el marco ideológico: los partidos conservadores, con la excepción de Francia, se mostraron más proclives a aprobar las acciones norteamericanas; los de izquierdas manifestaron una oposición sistemática a las políticas de Estados Unidos. Además, y principalmente en aquellos países en los que el Gobierno defendía la postura de la Administración Bush, apareció una tercera ruptura entre el Ejecutivo y la opinión pública, que, de forma generalizada en toda Europa, se proclamó contraria a la guerra.

En este escenario, se entiende que los medios de comunicación europeos mostraran el mismo interés por el debate que suscitó la intervención armada que por los hechos violentos

1 FREEDMAN. Lawrence. “War in Iraq: selling the truth". Survival. Vol. 46, núm. 2, 2004, pp. 7-50. 
que tuvieron lugar en Irak. Así, especialmente en los meses que siguieron a las operaciones militares propiamente dichas, sin dejar de prestar atención a los acontecimientos de la posguerra, los medios dieron prioridad a los "actos colaterales" que el conflicto estaba provocando en sus países.

Ese comportamiento no respondía solo a un criterio de interés informativo. Si la capacidad militar es necesaria para ganar la guerra, la credibilidad lo es para ganar el debate político. Lo que estaba en juego era la reputación de Estados Unidos y la de todos los defensores de la intervención de las fuerzas armadas en Irak. ${ }^{2}$ En esas circunstancias, la interpretación de los hechos es más decisiva que los hechos en sí. Los medios de comunicación adquieren, entonces, una importancia mayor de lo habitual como instrumentos para incidir en la opinión pública $^{3}$ y sus contenidos reflejan las presiones a las que son sometidos por parte de los actores políticos comprometidos en el conflicto, que compiten por conseguir que la primera versión de los acontecimientos que se difunda coincida con su visión particular. ${ }^{4}$
En el presente trabajo consideraremos un elemento esencial para el discurso político que es la imagen de Estados Unidos en los informativos de las principales emisoras de televisión públicas y privadas en Europa. En particular, interesa el enfoque con que se cubren las declaraciones de los principales protagonistas de la guerra de Irak, el tipo de valores que subrayan y los argumentos que hacen referencia a la legitimidad del uso de la fuerza y a los principios del orden internacional. Las conclusiones del análisis permitirán describir los elementos que determinan la credibilidad de Estados Unidos como líder político.

La aportación del estudio puede resultar especialmente interesante en un momento en que la elección del nuevo presidente, Barack Obama, ha despertado una positiva expectación, suspendiendo todos los juicios emitidos por el momento sobre Estados Unidos y su política exterior. El reciente viaje a Europa del entonces candidato demócrata ha cambiado la abierta condena a la Administración Bush en una esperanza de cambio. Sin embargo, las conclusiones de este

2 HAMMOND, Philip. "Postmodern war in Iraq", en NIKOLAEV, A. y E. HAKANEN (eds.). Leading to the 2003 Iraq war: the global media debate, 2006, pp. 85-96.

3 BARABAS, Jason. Certitude: Uncertain Knowledge and Message Clarity in Mediated Deliberation, 2005.

4 LA PORTE, M. T. “Efectos de los medios en las controversias internacionales”, en RODRÍGUEZ, R. y T. SÁDABA (eds.). Periodistas ante conflictos, 1999, pp. 79-94. 
análisis permiten afirmar que la actitud de Europa hacia Estados Unidos se fundamenta sobre principios, valores y actitudes que no se modifican solo con imagen y buenas palabras y que requieren habilidad $y$ autenticidad política.

\section{Evolución del antiamericanismo europeo}

A pesar de su indudable poder, los medios de comunicación están condicionados por un entorno político y social que les antecede e influye y que es necesario considerar para una correcta interpretación de sus contenidos. En este caso, es importante examinar la evolución y consistencia del llamado antiamericanismo europeo.

El antiamericanismo podría definirse como

[...] una disposición poco favorable hacia los Estados Unidos que conduce a los individuos a interpretar las acciones estadounidenses a través de prejuicios y estereotipos negativos. ${ }^{5}$

En la era de la globalización, el antiamericanismo adquiere un matiz específico: la palabra americanización se identifica con el proceso de dominio de tendencias culturales que provienen de Estados Unidos, produciendo una relación de subordinación económica, cultural y política en las sociedades que son afectadas. ${ }^{6}$

El antiamericanismo en Europa tiene una larga tradición. También es mucha la producción científica que analiza las causas y diferentes manifestaciones de ese resentimiento y que se desarrolla de forma paralela a un antieuropeísmo americano (Miller ${ }^{7}$ y Applebaum $^{8}$ aportan una revisión bibliográfica interesante). Para el objeto de este trabajo baste con señalar los aspectos políticos y culturales que mejor pueden explicar las diferentes posturas europeas en la guerra de Irak.

Las relaciones entre Estados Unidos y Europa atraviesan una de las crisis más agudas de su historia. Aunque se manifiesta de forma particular en el debate de la guerra de Irak, empieza a generarse tras el discurso sobre el Estado de la Nación pronunciado por el presidente Bush el 29 de enero del 2002, cuando este revela las líneas maestras de la política exterior

5 MEUNIER, Sophie. "Anti-Americanisms in France". European Studies Newsletter Council for European Studies. Vol. XXXIV, núm. 3/4, enero del 2005, p. 1.

6 SCHOU, S. "Postwar americanization and the revitalization of european culture", en SKOVMAND, M. y K. SCHRODER. (eds.). Media cultures: Reappraising trasnational media, 1993.

7 MILLER, Toby. "Anti-americanism and popular culture". Anti-Americanism Working Paper, 2005.

8 APPLEBAUM, Anne. In search of Pro Americanism in Foreign Policy. Julio-agosto del 2005, pp. 32-40. 
norteamericana tras el atentado del 11 de setiembre. Es decir, los principios del war on terror. Resulta excesivamente simple hablar de una posición europea común, pero sí puede afirmarse que la visión que el Presidente expone en ese discurso despierta un recelo generalizado en el viejo continente que, por primera vez desde la Guerra Fría, no comparte los términos en que Estados Unidos entiende la política de seguridad mundial.

\section{Divergencias en la política de seguridad}

Hasta 1990, Europa asumió sin excesivo problema la primacía internacional de Estados Unidos y prestó su apoyo siempre que fue requerido. Es preciso admitir que obtuvo indudables beneficios de esa situación: desde la rehabilitación y reconstrucción de los primeros años de la Guerra Fría hasta la continua garantía de seguridad y defensa frente al bloque soviético. Por su parte, Estados Unidos también se vio favorecido con el respaldo europeo: bien con una colaboración directa, como la cesión de espacio para el establecimiento de las bases militares, o bien de forma más indirecta, con un silencio discreto ante operaciones dudosas, como algunas de las desarrolladas en Centroamérica (Granada y Panamá, por ejemplo). Esa complementariedad de intereses no logró eliminar ni el tradicional recelo europeo hacia Estados Unidos ni el también legendario antieuropeísmo americano. ${ }^{9}$ Pero ese enfrentamiento latente, de carácter más cultural, apenas tuvo incidencia en las relaciones políticas desarrolladas durante la Guerra Fría.

En los años noventa comenzó el debate en torno al nuevo orden internacional ocasionado fundamentalmente por la desaparición de la Unión Soviética. Pero es un debate eminentemente teórico, que aporta pocas ideas a la resolución práctica de los conflictos y que discurre en forma pacífica. En el ámbito económico, el mercado norteamericano se expandió hasta hacerse global y el europeo procuró crecer a través de la consolidación de la Unión Europea. Las principales diferencias se dieron en la competencia comercial internacional, especialmente en lo relativo al mercado de productos audiovisuales ${ }^{10}$ y políticas agrarias.

9 Véase GARTON ASH, Timothy. "Anti-europeism in America". New York Review of Books, 13 de febrero del 2003.

10 LA PORTE, T. et al. "Globalization of the media industry and possible threats to cultural diversity" [en línea]. <http://www.europarl.eu.int/stoa/publi/pdf/summaries/00-1301sum_es.pdf>. 
A partir del 2002, se puso de manifiesto una visión diferente del contexto de la seguridad mundial en el siglo XXI. Siguiendo el análisis de Serfaty, se puede afirmar que había una diversa percepción de la amenaza y una divergente consideración de los medios que podían utilizarse para garantizar la paz. ${ }^{11}$

Tras los atentados del 11 de setiembre, los norteamericanos entendieron que se abría una nueva etapa (New normalcy, en palabras de Dick Cheney) ${ }^{12}$ sin precedente en su historia inmediata: la guerra, un acontecimiento que habitualmente se desarrollaba en algún lugar lejano (over there), ocurría por primera vez en territorio norteamericano (over here). Los medios de comunicación se encargaron de reforzar esa percepción repitiendo la referencia al ataque japonés de Pearl Harbour en la cobertura de los días posteriores al atentado del World Trade Center. ${ }^{13}$ Las declaraciones eventuales de Sadam Hussein sobre la intención de utilizar armas químicas de destrucción masiva en caso de necesidad agudizaron todavía más la impresión de la inminencia de la amenaza. Estados Unidos, en suma, consideró perdida la invulnerabilidad que había caracterizado hasta el momento al país y sintió la urgencia de restablecer las condiciones de seguridad anteriores. Europa, por el contrario, tenía una experiencia histórica diferente ya que ha padecido ataques terroristas con mayor frecuencia. Por ello, aunque asumía la gravedad de la situación, fue más cauta a la hora de valorar la inmediatez de la amenaza.

En relación con los medios que debe contemplar una política de seguridad, Europa prefiere confiar en las organizaciones internacionales, utilizando la vía del multilateralismo, y anteponer la acción diplomática a la militar. Aunque Estados Unidos hubiera aprobado ese modo de proceder en momentos anteriores, no parece suficiente en la situación creada desde el 2001: el recurso a la fuerza militar se contemplaba como una medida necesaria como condición previa para crear un marco de seguridad global.

Europa estuvo de acuerdo con actuar de esa forma en el caso de Afganistán, porque la relación con $\mathrm{Al}$ Qaeda y el integrismo islámico era más evidente y porque la colaboración se desarrollaba en el marco de la

11 SERFATY, Simon. La France vue d'Amérique: Reflexions sur la francophobie á Washington, 2002.

12 El término New normalcy fue utilizado por primera vez por Dick Cheney en una entrevista publicada en el Washington Post, el 21 de octubre del 2001.

13 SADABA, T. y LA PORTE, M. T. “Mediated terrorism in comparative perspective: Spanish press coverage of 9/11 vs. coverage of basque terrorism", en KAVOORI, A. y FRALEY, T. (eds.). Mediated terrorism: Readings in theory, 2005, pp. 69-90. 
OTAN. La confrontación con Estados Unidos y entre los gobiernos europeos se produjo al tener que admitir el concepto de intervención preventiva (preemptive war) que defendía la Administración Bush para el caso de Irak: mientras que para los norteamericanos y algunos de los gobiernos europeos la posibilidad de que Sadam tuviera armas de destrucción masiva justificaba una intervención armada, para países como Francia y Alemania o para la mayoría de la opinión pública europea la simple sospecha no era argumento suficiente para declarar la guerra.

Estados Unidos percibió la posición europea como poco realista $y$ más fundamentada en una actitud pasiva y reacia al gasto en defensa que en un análisis riguroso de la situación. Como afirma Serfaty, "[...] lo que de fondo separa las dos posiciones no es tanto una tensión entre poder y debilidad, sino entre fuerza y orden". ${ }^{14}$

\section{Resurgir del antiamericanismo en Europa}

Pero no se trataba solo de una diferente posición estratégica: la reacción política hizo resurgir un antiamericanismo de carácter más cultural. Fue protagonizado por los movimientos pacifistas, que rechazaron abiertamente la actitud beligerante de Estados Unidos, y respaldado por el conjunto de la opinión pública. Sin embargo, de fondo existía un recelo que tiene raíces más profundas y que, rescatando solo los argumentos útiles para el presente trabajo, podríamos resumir considerando algunos aspectos históricos y culturales.

Para algunos autores, una de las causas del antiamericanismo europeo es la evolución de su propia historia. En primer lugar, por lo que ha significado la pérdida del liderazgo internacional a favor de Estados Unidos. A pesar de no haber dudado en beneficiarse de su poder político y militar en momentos de riesgo para su seguridad, el sincero agradecimiento europeo no consiguió eliminar los deseos de restablecer el pasado y compartir con Estados Unidos el protagonismo internacional. ${ }^{15}$ Esta actitud difiere de un país europeo a otro, dependiendo de cuál haya sido su historia particular. Pero todos coinciden en revitalizar la Unión Europea para crear un espacio propio y en contraponer una posible política exterior comunitaria a la desarrollada por la OTAN. Junto a ello, otra postura común es buscar siempre entornos multilaterales donde el poder americano quede diluido. En la actualidad, Euro-

14 SERFATY, Simon. Op. cit., p. 15.

15 Ibídem. 
pa acusa en forma especialmente negativa las decisiones unilaterales norteamericanas (Irak, pero también la actitud hacia el tratado de Kioto, el Tribunal Penal Internacional o los vuelos secretos de la CIA por el espacio europeo) y que su poder se vea reducido a seguir o no el dictado de Washington.

La segunda causa del antiamericanismo europeo es el rechazo al recurso de las armas. Según afirma Kagan, la devastación que han supuesto las dos guerras mundiales, la división del continente durante la Guerra Fría y las múltiples experiencias de terrorismo han provocado que Europa tenga una percepción diferente de lo que constituye una amenaza para la paz y la libertad. Y explica también que prefiera aplicar los instrumentos políticos y legales para resolver los conflictos en lugar de acudir al uso de la fuerza. ${ }^{16}$

En relación con los valores culturales, hay que admitir que la diferencia es mínima. Europa comparte la mayor parte de los valores característicos de la cultura americana y defiende los mismos principios y libertades. De hecho, han sido muchas las ocasiones en que han luchado juntos por las mismas causas. Sin embargo, dentro de ese marco general que identifica las democracias occidentales, Europa difiere de Estados Unidos en el rechazo a prácticas como la pena de muerte, la libertad del comercio de armas, la debilidad de la agenda social en los asuntos públicos o la libre competencia en el mercado internacional. En los últimos años, a la relación anterior se añade la presencia de valores religiosos en la argumentación política y en los discursos públicos americanos. ${ }^{17}$ Este antiamericanismo prevalece en la izquierda laicista europea y se torna más radical cuando la Administración norteamericana es republicana.

No puede dejar de mencionarse también cómo contribuyen a ese espíritu antiamericano europeo los productos de entretenimiento de Hollywood: esos contenidos, junto con otros aspectos como pueden ser el idioma o los valores presentes en la publicidad comercial, son percibidos como una manifestación de imperialismo cultural. ${ }^{18}$

A todo lo anterior se unen las críticas de los adversarios de Bush sobre su cualificación personal para ejercer el cargo de Presidente. El escaso margen de votos con que ganó las primeras elecciones y algunas declaraciones poco apropiadas cuestionaron desde

16 KAGAN, Robert. Of Paradise and Power: America and Europe in the New world order, 2003.

17 WEIGEL, George. Política sin Dios, 2005.

18 MILLER, Toby. Op. cit. 
el principio del mandato su credibilidad como líder internacional.

\section{Las posiciones europeas en relación con el conflicto de Irak}

¿Cómo se decanta esa divergencia política y cultural en un conflicto como el de Irak? Las reacciones de gobiernos y ciudadanos, siendo similares en los aspectos más básicos, mostraron también algunas diferencias.

\section{Reacción de los gobiernos}

La relación del Reino Unido con Estados Unidos ha sido siempre muy estrecha: la política exterior británica se ha movido preferentemente en un ámbito atlantista y no tanto europeísta. Sin embargo, en la actualidad ha comenzado un proceso de revisión de esas relaciones como consecuencia de la necesidad de adaptarse a nuevas circunstancias. ${ }^{19}$ Esas nuevas circunstancias vienen marcadas por la necesidad de evolucionar hacia una visión más pragmática y menos sentimental de la política exterior. Esta postura obliga al reconocimiento de que la relación con Estados Unidos es excesi- vamente desigual y no puede continuar siendo exclusiva. Aconseja también admitir una progresiva e inevitable europeización y anima a atender la presión de una opinión pública que cada vez se torna más europeísta ${ }^{20} \mathrm{y}$ que en forma mayoritaria ha rechazado la guerra en Irak. A pesar de todo ello, el gobierno de Blair -o mejor dicho, Blair - mantuvo indeleble su apoyo a la política war on terrorism de Estados Unidos. ${ }^{21}$ Las palabras que dirigió a sus bases políticas el 2001 tienen hoy plena vigencia: "Whatever the dangers of the action we take, the dangers of the inaction are far, far greater" (conferencia en el Partido Laborista, octubre del 2001). Esa actitud ha generado, según algunos autores, ${ }^{22}$ el resurgir de un nuevo antiamericanismo británico, provocado en primera instancia por el rechazo a las políticas de Tony Blair.

Francia representa la postura opuesta. El rechazo de la intervención americana en Irak es perfectamente coherente con la tradición política de este país. Siempre ha querido mantener una libertad de acción con respecto a Estados Unidos y ha sido partidario de un planteamiento multilatera-

19 HILL, Christopher. "Dilemmas of a Semi-Insider: Blairite Britain and the United States", en BALIS, Christina V. y S. SERFATY. Visions of America and Europe: September 11, Iraq, and transatlantic relations. Significant Issues Series. Vol. 26, núm. 3, 2004, pp. 91-115.

20 EUROPEAN COMMISSION. Standard Eurobarometer 65, 2006.

21 The Economist. "Axis of feeble", 2006, p. 11.

22 DEER, Patrick. "The dogs of war: Myths of british anti-americanism", en ROSS, Andrew y Kristi ROSS. Anti-americanism, 2004, pp. 158-178. 
lista. Hay quien afirma, sin embargo, que la insistencia en dirimir los conflictos internacionales en la ONU o el pacifismo que caracteriza sus discursos políticos no son sino intentos de minar o controlar el liderazgo norteamericano. ${ }^{23}$ Sea cual fuere la causa de la política exterior francesa del momento, lo evidente fue que representó y lideró la oposición europea a la Administración Bush.

La historia de Alemania es la mejor explicación para entender la oposición al uso de la fuerza y la preferencia por resolver los conflictos en forma pacífica. Su reacción ante la guerra de Irak era, por tanto, previsible. Lo que resulta sorprendente, sin embargo, es su antiamericanismo, siendo este un rasgo nuevo en las relaciones entre Estados Unidos y Europa. A Alemania siempre le ha ido mejor cuando ha mantenido un contacto fluido con Washington, y también a los norteamericanos, que podían así dejar a Francia aislada. Lo que no entiende es la postura de Estados Unidos en temas como Kyoto o el Tribunal Penal Internacional. Por otra parte, los alemanes rechazan la postura de dominio norteamericana que ellos mismos padecieron en la situación creada tras la Segunda Guerra Mundial: según Nolan, lo que constituye una polémi- ca no es la cultura norteamericana sino su poder. Por eso, el nuevo antiamericanismo alemán es político antes que cultural; la crítica contra el capitalismo está motivada por intereses sociales y ecologistas pero no son propiamente anticapitalistas o antimodernidad. $^{24}$

El apoyo de José María Aznar a la guerra de Irak supuso uno de los mayores quiebros entre un dirigente político y la opinión pública, que rechazaba en más de 90 por ciento la intervención. Tras los atentados del 11 de marzo del 2004, José Luis Rodríguez Zapatero llegó al Gobierno con la promesa de retirar las tropas. Este contexto político hizo resurgir el antiamericanismo español como un argumento principal en el debate entre los partidos políticos.

El antiamericanismo en España está ligado ideológicamente a la izquierda y al pacifismo de la cultura política. Hay que recordar que, de acuerdo con las escalas de autoubicación ideológica, España se sitúa siempre con las mayores tendencias de izquierdas de Europa (desde 1980 se ha mantenido en el 4,7 en la escala en la que 1 es la izquierda, 5,5 el centro y 10 la derecha). También la idea del pacifismo está ampliamente asentada. Así se explican el rechazo que supuso

23 PARMENTIER, Guillaume. The United States Today, 2004; KAGAN, Robert. Op. cit.

24 NOLAN, Mary. "Anti-americanization in Germany", en ROSS, Andrew y Kristi ROSS. Anti-americanism, 2004, p. 126. 
la instalación de bases americanas en España, el apoyo de Reagan a las dictaduras militares de América Latina, o la postura que se tuvo en un principio ante la OTAN. La guerra de Irak no ha hecho sino acrecentar este sentimiento de aversión a la política norteamericana, que además encuentra en la figura de Bush el máximo exponente de los valores que se rechazan.

\section{Reacción de la opinión pública}

La opinión pública europea sobre los Estados Unidos ha dado un giro radical en los últimos años: el respaldo incondicional del 2001 se ha trocado en una abierta condena y falta de credibilidad. La reciente elección de Barack Obama ha modificado sustancialmente esa actitud, mostrando que el antiamericanismo era propiamente una actitud anti-Bush. Pero, por el momento, el juicio se suspende con una espera expectante al cambio prometido por el nuevo Presidente.

Tras los atentados perpetrados contra las Torres Gemelas de Nueva York y el Pentágono, todas las naciones manifestaron en forma unánime su condolencia y respaldo, al tiempo que condenaban terminantemente los actos terroristas. Baste recordar ahora el titular de Le Monde del 12 de septiembre del 2001 ("Todos somos americanos") para reflejar la entidad del cambio con el ejemplo de Francia, que luego lideraría la oposición a la intervención en Irak.

En marzo del 2003, tras las fuertes discusiones mantenidas en la ONU en torno a Irak, las actitudes positivas habían disminuido considerablemente, tanto en los países musulmanes como en los aliados europeos. El estudio de The Pew Research Center for

Actitudes hacia Estados Unidos (\%)

\begin{tabular}{|c|c|c|c|c|c|}
\hline \multirow{2}{*}{ País } & \multicolumn{3}{|c|}{ Favorable } & \multirow{2}{*}{$\begin{array}{c}\text { Desfavorable } \\
\text { Antes de } \\
\text { marzo del } 2003\end{array}$} & \multirow{2}{*}{$\begin{array}{c}\text { Opuesta } \\
\text { Marzo del } 2003\end{array}$} \\
\hline & 2000 & 2002 & Marzo del 2003 & & \\
\hline Reino Unido & 85 & 75 & 48 & & \\
\hline Alemania & 78 & 61 & 25 & & \\
\hline $\begin{array}{l}\text { Líbano, Egipto, } \\
\text { Jordania, Pakistán }\end{array}$ & & & & 60 a 70 & \\
\hline Turquía & & & & 60 a 70 & 42 \\
\hline
\end{tabular}

Fuente: The Pew Research Center for the People \& the Press, 2003. 
the People \& the Press del 2003 facilitaba los siguientes datos:

Otros datos que demuestran la falta de credibilidad de las tesis norteamericanas son los siguientes. A pesar del esfuerzo por convencer acerca de la amenaza que suponía para la paz mundial la posesión de armas de destrucción masiva por parte de los países del "eje del mal", una encuesta realizada por la revista Times a 250.000 europeos en el mismo año, mostraba que un 87 por ciento de la población consideraba que Estados Unidos era precisamente el principal riesgo para la paz mundial, en contraste con un 8 por ciento que opinaba que lo era Irak y un 9 por ciento que optaba por Corea del Norte. ${ }^{25}$ Esta crítica se hacía especialmente patente en países árabes y musulmanes en los que, según los resultados obtenidos por Zogby Internacional en junio del 2004, la opinión favorable a los Estados Unidos se había reducido considerablemente, en este caso no solo por la guerra en Irak sino también por la condena a la postura norteamericana en el conflicto de Palestina. Este clima de opinión afectó también a Europa, por cuanto las comunidades de inmigrantes musulmanes suelen compartir el parecer de la opinión pública de sus países de origen.

En el último estudio publicado en junio del 2006 por el Pew Research Center sobre la imagen global de Estados Unidos en 15 naciones, se afirmaba que tanto la imagen como el respaldo a la lucha antiterrorista habían descendido hasta en aliados como Japón. En esta encuesta se ofrecen también datos muy significativos sobre la evolución de las percepciones

Opiniones favorables hacia Estados Unidos (\%)

\begin{tabular}{lcccccc}
\hline & $\mathbf{1 9 9 9 - 2 0 0 0}$ & $\mathbf{2 0 0 2}$ & $\mathbf{2 0 0 3}$ & $\mathbf{2 0 0 4}$ & $\mathbf{2 0 0 5}$ & $\mathbf{2 0 0 6}$ \\
\hline Reino Unido & 83 & 75 & 70 & 58 & 55 & 56 \\
Francia & 62 & 63 & 43 & 37 & 43 & 39 \\
Alemania & 78 & 61 & 45 & 38 & 41 & 37 \\
España & 50 & -- & 38 & -- & 41 & 23 \\
\hline
\end{tabular}

Fuente: The Pew Research Center for the People \& the Press, 2006.

25 Times; PILGER, John. "We see too much. We know too much. That's our best defense". The Independent, 2003. 
en Europa sobre Estados Unidos desde principios del nuevo siglo.

El estudio diferenciaba la imagen que se percibe en la opinión pública global del conjunto del país de la que se tiene de sus ciudadanos y demostraba la misma tendencia que en trabajos anteriores: existe una opinión más positiva de los norteamericanos que de Norteamérica.

Con respecto a la guerra de Irak, en tres de los cuatro países europeos examinados (Alemania, Francia, España) el estudio de 2006 demostraba que las opiniones desfavorables sobre Estados Unidos habían aumentado como consecuencia de una percepción negativa de la guerra de Irak. En Reino Unido se apreciaba una tendencia a la baja en las opiniones favorables, aunque se mantenía cierto optimismo sobre la intervención en Irak.

Con los datos de estos sondeos se puede afirmar, sin lugar a dudas, que la guerra de Irak y la llamada "guerra contra el terrorismo" generaron un nuevo factor que incrementó la percepción negativa sobre Estados Unidos. Como concluía el Pew Center, la Guerra de Irak ha ensanchado la fractura entre los americanos y los europeos del Oeste.

\section{Los medios de comunicación y la guerra de Irak}

Como es sabido, los medios de comunicación actúan como mediadores entre las fuentes y la audiencia, conservando una relación específica con ambas partes. ${ }^{26}$ Es un proceso de transacción de información entre los primeros y los segundos en el que los medios aportan sus propios valores. Esos valores constituyen una cultura específica que viene determinada por aspectos que proceden del exterior (como las regulaciones sobre comunicación pública) y del interior (rutinas y prácticas profesionales). Por lo tanto, se puede afirmar que los medios no actúan como simples transmisores sino que contribuyen a "construir la realidad". En este caso, podríamos afirmar que los medios europeos actúan en un entorno político definido como antiamericano y contrario a la guerra de Irak, que, a la vez, alimentan y les influye.

Además, y para cuestiones que la gente no experimenta directamente, como es la realidad de otro país o una guerra, la influencia de los medios al explicar la realidad aumenta: la interpretación de los hechos que la audiencia realiza depende en buena medida

26 GAMSON, W. A. “News as framing”. American Behavioral Scientist 33 (2), 1989, pp. 157161; WASBURN, P. C. The social construction of international news. We're talking about them, they're talking about us, 2002; JOHNSON-CARTEE, Karen S. News narratives and news framing: Constructing political reality, 2005. 
de la imagen transferida por los informativos. Es lo que Nimmo y Combs denominan mass-mediated reality. ${ }^{27}$ Harris y Karafa insisten en la misma línea, afirmando: "what people see frequently on TV, is what they come to believe". ${ }^{28}$ Concretamente, su análisis concluye que los medios de comunicación son la influencia más poderosa (especialmente la televisión y el cine) en la configuración de la imagen de un país. De este modo, puede suponerse que la manera en que los medios de comunicación cubran la guerra de Irak influirá en gran medida en la percepción de la opinión pública sobre Estados Unidos.

Con relación a la guerra de Irak, existen numerosos análisis sobre la cobertura realizada por los medios norteamericanos. El interés por este tema surge en gran medida por dos motivos fundamentales. Por un lado, la comparación con la primera guerra del Golfo. El papel de los medios en este conflicto fue ampliamente critica$\mathrm{do}^{29}$ tanto por su sometimiento a los dictados del Pentágono y la presentación de una clean war sin imágenes de víctimas, como por el dominio de la $\mathrm{CNN}^{30}$ Por otro lado, los análisis se centran en la novedad que ha supuesto esta guerra en relación con los medios, con los embedded journalists. ${ }^{31}$

Según algunos autores, los medios no han cambiado en su comportamiento respecto a la primera guerra del Golfo. De nuevo, se trata de una guerra sin víctimas en los medios: "[...] the proportion of firefight to casualty images was overwhelmingly in favor of the former, and the dead were rarely shown at all"32 y en la que los periodistas no ayudan a acercar el

27 NIMMO, Dan y J. E. COMBS. Mediated political realities, 1983.

28 HARRIS, R. J. y J. A. KARAFA. "A cultivation theory perspective of World Wide National Impressions of the United States", en KAMALIPOUR, Y. R. Images of the US around the world. A multicultural perspective, 1999, p. 4.

29 IYENGAR, S. y A. SIMON. "News coverage of the Gulf crisis and public opinion". Communication Research, 20 (3), 1997, pp. 365-383; BENNETT, W. L. y D. PALETZ. Taken by storm. The media, public opinion and US foreign policy in the Gulf war, 1994; MOWLANA, H.; GERBNER, G. y H. SCHILLER (eds.). Triumph of the image: the media's war in the Gulf. A global perspective, 1992.

30 BENNETT, W. L. y S. LIVINGSTON. “Gatekeeping, indexing and live-event news: Is technology altering the construction of news?". Political Communication 20, 2003, pp. 363-380.

31 TUMBER, Howard y Jerry PALMER. Media at war. The Iraqi crisis, 2004; KATOVSKY, Bill y Timothy CARLSON. Embedded: The media at war in Iraq, 2003.

32 ADAY, Sean. "The real war will never get on television an analysis of casualty imagery in american television coverage of the Iraq war", en SEIB, P. Media and conflict in the twentyfirst century, 2005, p. 17. 
conflicto. Algunos análisis apuntan a la falta de perspectiva de estos profesionales y al tono favorable hacia el ejército al que acompañan en los primeros días de la invasión. ${ }^{33}$ No obstante, otros trabajos también señalan que el resultado informativo final goza de suficiente objetividad. ${ }^{34}$

Sobre el comportamiento de los medios en Europa, los análisis más relevantes se han realizado en Alemania. Haumann and Petersen comparan los medios americanos con los alemanes durante la guerra de Afganistán, llegando a la conclusión de que los primeros se fijan más en las batallas y en las relaciones entre los gobiernos implicados mientras que los alemanes se detienen en la población civil y las pérdidas humanas. ${ }^{35}$ Otro estudio comparativo expone que no hay una visión crítica por parte de los medios en ninguno de los dos países de manera que los periodistas siguen a las fuentes oficiales, si bien hay ligeras diferencias, ya que la televisión alemana trata de incluir fuentes iraquíes y una perspectiva más internacional. ${ }^{36}$ El tema del seguimiento a las fuentes oficiales es bastante recurrente en todos los análisis sobre el conflicto. El dominio de estas fuentes oficiales se explica en ocasiones por un malentendido patriotismo de los medios tras el 11 de setiembre, que les aleja de su función crítica con el poder. ${ }^{37}$

Lewis compara la cobertura de la televisión inglesa con los cambios de la opinión pública en relación con la guerra. En sus conclusiones, apunta a que:

33 PFAU, M. et al. "Embedding journalists in military combat units: Impact on newspaper story frames and tone". Journalism and Mass Communication Quarterly 81, 2004, pp. 74-88.

34 ADAY, S.; LIVINGSTON, S. y M. HEBERT. "Embedding the truth: A cross-cultural analysis of objectivity and television coverage of the Iraq war". Press/Politics 10(1), 2005, p. 18.

35 HAUMANN, Wilhelm y Thomas PETERSON. "German public opinion on the Iraq conflict: A passing crisis with the U.S.A. or a lasting departure?". International Journal of Public Opinion Research 16, 2004, pp. 311-330.

36 LEHMANN, Ingrid. "Exploring the transatlantic media divide over Iraq: How and why U.S. and German media differed in reporting on UN weapons inspections in Iraq, 20022003". The Harvard International Journal of Press/Politics 10, 2005, pp. 63-89.

37 KELLNER, D. "September 11, the media, and war fever". Television E New Media, 3 (2), 2002, pp. 143-151; RYAN, Michael. "Framing the war against terrorism: U.S. newspaper editorials and military action in Afghanistan". The International Communication Gazette 66, 2004, pp. 363-382. 
[...] the absence of embeds with Iraqi forces and the norms of taste and decency made it difficult for broadcasters to show the more graphic images of death and destruction or the ugly side of war, creating a stream of footage that humanized the U.S.-led forces and dehumanized the Iraqis. ${ }^{38}$

A la misma conclusión llega un estudio realizado por la Cardiff School of Journalism, Media and Cultural Studies. ${ }^{39}$

El único análisis comparativo entre la cobertura de diversos países lo ha realizado Media Tenor. El análisis concluye que los medios alemanes son bastante más críticos con Estados Unidos que los británicos, concretamente, por este orden: ARD, ZDF, The Times y BBC.

Respecto a los medios franceses, el polémico libro de Alain Hertoghe, ${ }^{40}$ La guerre à outrances, ${ }^{41}$ afirma que los cinco principales periódicos franceses parten de un punto de vista demasiado ideológico y antiamericano sobre la guerra, con lo que pierden objetivi- dad y distancia. Un examen de Le Monde y su postura editorial revela algunos de estos presupuestos antiamericanos y la percepción en Francia de una creciente enemistad hacia ellos por parte de los medios en estadounidenses. $^{42}$

La novedad del análisis que se presenta en este trabajo es que recoge cuatro países europeos de modo comparado y examina la diferencia entre sus canales públicos y privados, a través de un análisis de contenido que combina el método cuantitativo y el cualitativo.

\section{La imagen de Estados Unidos en la televisión europea}

La televisión es el principal medio que tuvieron los europeos para informarse sobre la guerra de Irak, según los datos del Eurobarómetro (2004), en un 73 por ciento de los casos, seguido de la prensa en un 54 por ciento y la radio en un 35 por ciento.

Por otra parte, los informativos constituyen el tercer género de mayor

38 LEWIS, Justin. "Television, public opinion, and the war in Iraq: The case of Britain". International Journal of Public Opinion 16, 2004, p. 308.

39 Cardiff School of Journalism, Media and Cultural Studies. "The role of embedded reporting during the 2003 Iraq war", 2003.

40 Al publicar este libro, Hertoghe fue despedido del periódico donde trabajaba, La Croix.

41 HERTOGHE, Alain. La Guerre à Outrances, 2003.

42 OBAJTEK-KIRKWOOD, Anne-Marie. "Le Monde on a 'likely' Iraq war", en NIKOLAEV, Alexander G. y Ernest A. HAKANEN. Leading to the 2003 Iraq war: the global media debate, 2006, pp.129-147. 
audiencia, que representa el 18 por ciento de los espacios más vistos, por detrás de la ficción (46 por ciento) y de los programas de entretenimiento (36 por ciento), como se recoge en el Eurodata Televisión Worldwide (2005). La importancia de los informativos en la configuración de las opiniones resulta por lo tanto fundamental, aunque esto no significa que el resto de géneros televisivos carezca de interés. ${ }^{43}$

En Europa, el análisis de la cobertura televisiva exige considerar las emisoras públicas y privadas. Las cadenas públicas presentan diferentes características en los distintos países dependiendo de cómo son su financiación y gestión. ${ }^{44}$ Por su origen y su distancia de los intereses comerciales, se ha entendido que encarnan una supuesta independencia, si bien existe el problema del posible control por parte de los gobiernos. ${ }^{45}$ No se trata de cadenas minoritarias, sino que reúnen grandes audiencias y compiten por ellas con la televisión comercial, que tiene un desarrollo histórico normalmente más tardío. ${ }^{46}$

Cadenas analizadas por países (\%)

\begin{tabular}{lllll}
\hline País (fuente) & & Canal & $\begin{array}{c}\text { Audiencia 2001-2002 } \\
\%\end{array}$ & $\begin{array}{c}\text { Audiencia 2000-2001 } \\
\%\end{array}$ \\
\hline Francia & Púb. & TF1 & $32,5(2002)$ & $33(2001)$ \\
Mediametrie & Priv. & France 2 & 20,8 & 21 \\
Alemania & Púb. & ARD & $13,4(2001)$ & $13,4(2001)$ \\
AGF/Gfk & Priv. & RTL & 14,9 & 14,9 \\
España & Púb. & TVE1 & $24,9(2002)$ & $24,5(2000)$ \\
RTVE/Sofres & Priv. & T5(A3) & 20,1 & $22,3 / 21.5$ \\
R. UNIDO & Púb. & BBC 1 & $26,4(2002)$ & $26,6(2001)$ \\
ITC & Priv. & ITV & 23 & 29,8 \\
\hline
\end{tabular}

Fuente: The Media Map Yearbook, 2003, 2002, CIT.

43 COTTLE, Simon. "Mediatizing the global war on terror", en KAVOORI, A. y T. FRALEY (eds.). Mediated terrorism: Readings in theory, 2006, pp. 19-48.

44 Tradicionalmente, los canales públicos se han financiado a través de impuestos directos (licence fee en Gran Bretaña, redevance en Francia, etcétera, y un taxpayer también en Alemania). En España se mantiene un sistema mixto de financiación

45 WOLDT. R. y J. DRIES. Perspectives of Public Service Television in Europe, 1998.

46 La televisión comercial surge en tres de los cuatro países analizados en los años ochenta. El año de inicio de las emisiones de televisión privada en Francia, 1982; en Alemania, 1987; en España, 1990. En Reino Unido lo había hecho ya en 1955. 
La muestra del estudio procede de Francia, Reino Unido, Alemania y España. Los canales seleccionados son aquellos que tenían una mayor audiencia en los años 2001, 2002 y 2003.

El periodo de análisis fue determinado al azar: se seleccionaron todos los informativos emitidos en prime time $^{47}$ en las semanas del 22 al 28 de septiembre del 2003 y la semana del 20 al 26 de septiembre del 2004. La codificación de las unidades fue realizada por investigadores procedentes de cada país objeto de estudio.

El análisis de contenido combinó metodología cuantitativa y cualitativa, tanto de los textos como de las imágenes televisivas, teniendo en cuenta el tema, el protagonista o fuente de la información, y el enfoque o evaluación (positiva, negativa o neutra). En este sentido, se siguieron pautas contrastadas por otros trabajos de análisis de contenido en televisión. ${ }^{48}$

En total se analizaron 112 informativos, 14 por año y país, teniendo en cuenta que la mitad corresponde a la cadena pública y la otra mitad a la privada de máxima audiencia. Como unidad de análisis del estudio se en- tendió la noticia en sus distintas variantes. Así, se registraron los temas de todas las noticias, colas, reportajes, breves y entrevistas que fueron emitidas en cada espacio informativo. Se codificaron todas las secciones del programa, a excepción de los titulares, los avances y los resúmenes. De este modo, el total de noticias que aparecen en la muestra son 2.179. Con el análisis cuantitativo se pretende poner en contexto las noticias sobre Irak; es decir, valorar su impacto dentro de los informativos y su tratamiento con respecto a otras informaciones. Con el análisis cualitativo, además, se quieren exponer los principales argumentos utilizados por los medios para explicar el conflicto y su conexión con el posible antiamericanismo.

\section{Tendencias generales en los informativos europeos}

Los temas más relevantes son la política, los deportes y los crímenes. Dentro de la sección política aparecen muchas de las noticias sobre la controversia que genera Irak entre los distintos países y partidos políticos.

47 El prime time se determinó en cada país de acuerdo con el concepto que cada país tiene de esta franja horaria.

48 STEVENS, Daniel; ALGER, Dean; ALLEN, Barbara y John L.SULLIVAN. “Local news coverage in a social capital: Election 2000 on Minnesota's local news station". Political Communication 23, 2006, pp. 61-83; DRUCKMAN, James N. "Media matter: How newspapers and television news cover campaigns and influence voters". Political Communication 22, 2005, pp. 463-481; PETER, J.; LAUF, Edmund; SEMETKO, Holli. “Television coverage of the 1999 european parliamentary elections". Political Communication 21, 2004, pp. 415-433. 
Temas predominantes en los informativos de mayor audiencia (\%)

\begin{tabular}{lcccc}
\hline & \multicolumn{2}{c}{2003} & \multicolumn{2}{c}{$\mathbf{2 0 0 4}$} \\
\cline { 2 - 5 } & Público & Privado & Público & Privado \\
\hline Política & 18,2 & 14,7 & 19,6 & 14,6 \\
Deporte & 12,2 & 14,3 & 13,9 & 14,8 \\
Crimen & 11,9 & 14,9 & 8,2 & 11,7 \\
Infotainment & 8,5 & 12,3 & 7,3 & 10,5 \\
Economía & 7,5 & 5,7 & 6,6 & 6,4 \\
Sucesos & 5,9 & 7,3 & 8,2 & 9,2 \\
Guerra de Irak & 4,8 & 4,9 & 2 & 2,1 \\
Salud & 4,3 & 2,6 & 5,3 & 4,7 \\
Sociedad & 43 & 3,7 & 3,1 & 2,6 \\
\hline
\end{tabular}

Fuente: Elaboración propia.

Sin embargo, se optó por incluir una categoría propia con el tema de la guerra para ver su impacto en el resto de los informativos.

Se puede apreciar la relativa importancia que tiene la guerra de Irak en los informativos. En sí misma, y dejando de lado las implicaciones políticas que aparecen en la primera categoría, ocupa un séptimo lugar en el año 2003 y el último en 2004. Es muy destacable la tendencia a la reducción de este tipo de noticias de un año a otro. Además, el comportamiento de las cadenas públicas y privadas es, en este sentido, muy similar. En cuanto a los protagonistas de las noticias, hemos encontrado un alto nivel de nacionalización: la mayor parte de los protagonistas de las noticias son personajes del propio país, inclu- so para los temas de carácter internacional.

Si nos fijamos en los demás protagonistas, se aprecian significativas diferencias entre países. Para Reino Unido es evidente la importancia de los protagonistas norteamericanos más que la del resto de los países europeos, mientras que en Francia sucede lo contrario. En Alemania y España se observa la diferencia entre canales públicos y privados, al conceder los privados más importancia a los protagonistas norteamericanos que en los públicos, tendencia que también sigue la televisión británica.

Respecto a la valoración de la información sobre el país y los políticos norteamericanos, como se percibe en el cuadro inferior, es llamativamente negativa en algunas emisoras priva- 
Procedencia de los protagonistas de la información

\begin{tabular}{lcrcc}
\hline & Nacionales & UE & EE. UU. & Otros \\
\hline Francia (privada) & 68,0 & 9,4 & 5,5 & 17,1 \\
Fracia (pública) & 61,5 & 11,8 & 5,9 & 20,7 \\
Alemania (privada) & 53,0 & 12,2 & 13,0 & 21,7 \\
Alemania (pública) & 65,7 & 11,1 & 5,1 & 18,2 \\
España (privada) & 59,3 & 6,3 & 8,5 & 25,9 \\
España (pública) & 66,3 & 13,4 & 5,8 & 14,5 \\
Reino Unido (privada) & 76,9 & 1,5 & 7,7 & 13,8 \\
Reino Unido (pública) & 68,4 & 2,1 & 3,2 & 26,3 \\
\hline
\end{tabular}

Fuente: Elaboración propia.

Evaluación general de la imagen de Estados Unidos (\%)

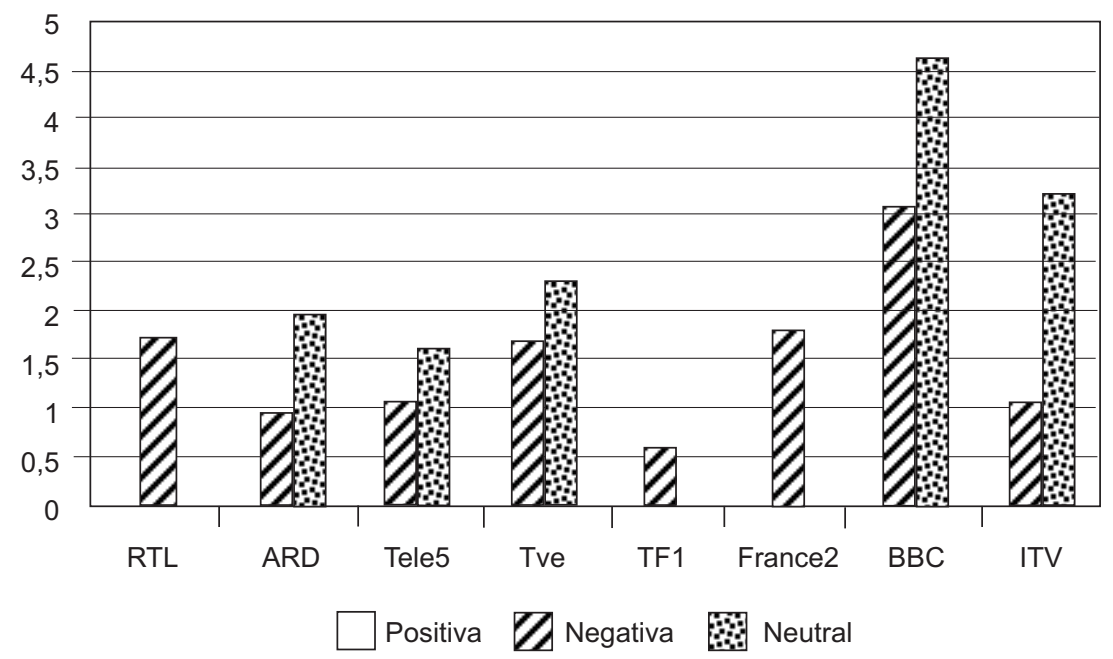

Fuente: Elaboración propia. 
das de Francia y Alemania, mientras que las demás cadenas, principalmente las públicas, intentan equilibrar una imagen negativa con otra más neutra. Reino Unido resulta, en este sentido, el menos parcial de los cuatro países analizados. En ningún caso, durante el periodo de análisis, la imagen fue positiva.

\section{Francia: Una visión crítica}

La situación de Francia respecto a la guerra de Irak define también la cobertura que presenta la televisión francesa. En este caso, hay una mayor homogeneidad, tanto en los dos años analizados como en los dos tipos de cadenas, ya que estas coinciden con la opinión pública en la visión crítica del conflicto.

Para la televisión francesa la prioridad es la violencia que se vive en Irak. Aunque se recogen las discusiones diplomáticas, resultan más relevantes los sucesos que tienen lugar en el campo de batalla, o las consecuencias que está teniendo la guerra para quien la vive de cerca, como los cooperantes o los periodistas. Por ejemplo, se hace una cobertura masiva de los secuestros.

Destaca la escasa presencia del aspecto político en la cobertura que hace la televisión francesa. Sin embargo, cuando se habla de cuestiones diplomáticas es significativo que en la cadena privada se da voz a todas las partes (hablan Bush, Chirac, e incluso
Kerry), mientras que en la pública solo se le da voz propia al presidente Chirac y sus intervenciones en Naciones Unidas.

Por el contrario, ciudadanos y expertos en la materia aparecen en muchas ocasiones en ambas cadenas. El tono de pesimismo respecto a la situación que se vive en Irak es el que predomina en todas las valoraciones.

La cadena privada France 2 no incluye en las cabeceras de sus informativos las noticias de Irak todos los días; sin embargo, en el desarrollo del noticiero aporta bastante contenido. Además, establece una práctica particular, puesto que cada día presenta un reportaje de fondo sobre un aspecto de la guerra. Por ejemplo, en una ocasión se hace un análisis de Arabia Saudí y el petróleo; en otro caso se presenta un monográfico sobre Al Zarqaui; en otro se habla de la vida de un reportero en Iraq.

La cadena pública, TF 1, presenta un ligero interés superior por las cuestiones diplomáticas que la privada. De hecho, es en esta cadena donde se subrayan las diferencias entre Chirac y Bush de los que se destacan distintos gestos de su distancia en su coincidencia en Naciones Unidas. Las dos cadenas recogen asuntos colaterales a esta guerra, sobre todo en relación con el mundo musulmán. En este sentido, se recoge como noticia los problemas de Cat Stevens, un cantante convertido al Islam al que no dejan entrar en Estados Unidos. 
Como es sabido, Francia encabezó la oposición política a la guerra de Irak, de manera que la cobertura de la televisión parece justificar esta postura al incidir en el desgaste y la inutilidad de la guerra. En todo caso, destaca la pluralidad de voces que se recogen para hablar del conflicto y además que este se "despolitiza" en cierta medida al dar bastante entrada a las voces de los iraquíes y de ciudadanos franceses o de los países que se ven afectados por los secuestros (italianos, británicos y norteamericanos). Es destacable también la presencia de los periodistas, pero que se limitan a introducir y guiar a la audiencia, sin tomar partido.

La crítica a la política norteamericana viene dada por los intereses que se vinculan a Estados Unidos en esta guerra: el petróleo y unas próximas elecciones. También se critica el unilateralismo norteamericano cuando se destaca el apoyo recibido al discurso de Chirac ante la ONU con su idea de la mundialización. En cualquier caso, la cobertura insiste en una idea dominante: la inestabilidad en Irak demuestra que la intervención no es eficaz.

Por último, merece la pena mencionar que la crítica se hace extensiva a Reino Unido y el gobierno de Blair, sobre todo respecto a su postura con los rehenes británicos. En este caso, las cadenas realizan varios reportajes con una perspectiva muy cercana a las familias y al lado más humano del tema, dejando notar la frialdad del gobierno de Reino Unido.

\section{Reino Unido: Tensión entre dos visiones}

La información británica sobre Irak está condicionada por dos noticias de gran repercusión nacional. El 2003, en el diario de Alstair Campbell se encuentra información relevante para el caso Kelly que puede inculpar al Gobierno británico; el 2004, los insurgentes han secuestrado a un británico y piden la retirada de las tropas como condición para su liberación. La imagen de Estados Unidos y la visión del conflicto de Irak son temas secundarios que se muestran solo como telón de fondo de los hechos anteriores.

La BBC cubre con extensión y detalle el proceso judicial abierto para comprobar la relación del gobierno con el caso Kelly. Es un tema crucial porque se debate y evalúa la credibilidad del principal argumento de Blair para implicar a Reino Unido en la guerra: la existencia de armas de destrucción masiva en Irak. Se cuestiona la honestidad de Blair y, por extensión, de Bush y de la legitimidad de la intervención armada como norma internacional. ${ }^{49}$

La emisora procura transmitir con la mayor precisión posible, repro-

49 FREEDMAN, Lawrence. Op. cit. 
duciendo frases textuales de la rueda de consultas realizada por el juez Hutton, fragmentos del diario de Campbell y cronologías muy detalladas sobre la sucesión de hechos. La noticia se mantiene por dos o tres días, con imágenes de búsquedas infructuosas de indicios de ese tipo de armas en Irak. La conclusión a la que parece llegar la BBC es: concedamos por el momento el beneficio de la duda, pero urjamos una explicación.

La cobertura de la Asamblea de la ONU se alterna con imágenes procedentes de Irak: el primer día, la inauguración del conclave en Nueva York se completa con la noticia sobre la explosión del coche bomba en la sede de Naciones Unidas en Bagdad. El discurso de Bush solicitando ayuda para conseguir la estabilidad de Irak se respalda con testimonios de voluntarios y médicos iraquíes que desde Bagdad reclaman recursos para la atención de los enfermos. También parecen favorables a la posición norteamericana las noticias sobre la efectividad de Guantánamo, donde se han localizado a dos presuntos miembros de Al Qaeda. Sin embargo, a las palabras del presidente Bush se contraponen siempre las declaraciones de Kofi Annan y de otros mandatarios opuestos a la política de Washington.

En septiembre del 2003 la sesión inaugural de la Asamblea de la ONU domina la información relativa a Irak. En el caso de la BBC, esa cobertura, más política, se alterna con noticias que proceden directamente de la zona del conflicto, estableciendo una relación directa entre las conversaciones de Nueva York y los atentados de Bagdad. El periodo analizado del 2004 coincide con el secuestro del británico Bigley y, lógicamente, las noticias en este país están dominadas por esta información. La BBC introduce el informativo con esta noticia durante toda la semana y le dedica una media de siete minutos de duración; Channel 5 también le otorga prioridad sobre otras noticias, aunque no siempre ocupa el primer lugar del informativo y la duración es más corta. Una diferencia interesante entre ambas emisoras es el enfoque del tratamiento de esta información: la BBC lo encuadra en un marco político, recogiendo las intervenciones y análisis de mandatarios y valorando la repercusión de las soluciones que se barajan para el conjunto del conflicto. Channel 5, por el contrario, presenta el escenario más violento: no deja de cubrir otros atentados de menor relieve que también tienen lugar en Irak y concede bastante extensión al secuestro de las rehenes italianas. También refleja el lado más humano de la noticia, recurriendo a la familia de Bigley, con exceso de sentimentalismo en alguna ocasión.

Ambas emisoras procuran un equilibrio en la selección de las fuentes, aportando la diferente visión de unos y otros. En el caso de la BBC, junto al vídeo del propio Bigley suplicando ser liberado y las declaracio- 
nes de su hermano, aparecen los protagonistas políticos valorando esta nueva táctica de los insurgentes en el conjunto del conflicto. Blair y Bush expresan con contundencia su mensaje: no hay negociación posible con los terroristas. Bush y Rumsfeld, a pocas semanas de las elecciones, insisten en demostrar que las tropas estadounidense no pueden abandonar Irak en la situación de inestabilidad existente. Koffi Annan condena con igual fuerza el secuestro de rehenes y el maltrato de prisioneros iraquíes en las cárceles norteamericanas.

La BBC, a través de sus propios corresponsales o relatando noticias secundarias de Irak, abre incógnitas para la consideración de la audiencia: la toma de rehenes y la inestabilidad actual de Irak ¿son la continuación de la guerra o un nuevo conflicto?; ¿es un enfrentamiento de los bandos leales a Sadam Hussein contra las fuerzas internacionales o hay atisbos de guerra civil y enfrentamientos con el gobierno recién constituido?; ¿es soberano el gobierno provisional iraquí o depende todavía de Washington?

Channel 5 prefiere una cobertura más localista y muy crítica hacia Blair. Recoge todas las intervenciones de la familia de Bigley a favor de su liberación, así como las de su Iglesia y de sus amigos. Compara el caso con la masiva reacción de la población italiana para defender a sus dos voluntarias también secuestradas. Contrasta con la frialdad y brevedad de las intervenciones de Blair afirmando que no puede hacer nada. El tono crítico se subraya a través de diferentes recursos. Por ejemplo, informa sobre un antiguo correo electrónico enviado a Powell y a Bush sugiriendo que refuercen el mensaje de amenaza de Sadam Hussein sobre los misiles. El periodista, con la intención de demostrar la debilidad del discurso político norteamericano, pregunta en tono de humor: "Y ahora, ¿dónde están los misiles?" En noticias posteriores insiste en la falta de pruebas para demostrar que Irak tuvo armamento químico o nuclear, en las consecuencias económicas de una estancia prolongada de sus tropas, en el sufrimiento de la familia de Bigley.

Podemos concluir que la cobertura del conflicto de Irak en la televisión británica, por la importancia de las consecuencias en la política y credibilidad de Blair, tiene un enfoque principalmente doméstico: apenas puede deducirse una imagen específica de Estados Unidos y tampoco refleja el enfrentamiento con otras naciones europeas. Sí están presentes, sin embargo, la fractura ideológica y de la opinión pública. Como sucede en la prensa, ${ }^{50}$

50 RAVI, Narasimhan. “Looking beyond flawed journalism: How national interest, patriotism, and cultural values shaped the coverage of the Iraq war". The Harvard Journal of Press Politics, Vol. 10, núm. 1, 2005, pp. 45-62. 
la televisión muestra la diversidad de opiniones que también caracteriza el espectro político británico. Los informativos reflejan el mismo enfrentamiento que tiene lugar en el Parlamento: la oposición de la mayor parte de los partidos Laborista y Liberal y el respaldo tibio del Partido Conservador. Por otra parte, tampoco dejan de mostrar la diversidad de posiciones en la ciudadanía

\section{Alemania: El compromiso con el pacifismo}

La cobertura de las emisoras alemanas refleja un interés prioritario por los efectos políticos del conflicto de Irak. El desarrollo de las negociaciones diplomáticas entre Europa y Estados Unidos prevalece en forma clara sobre los acontecimientos, generalmente violentos, que suceden en aquel país. Este comportamiento es más llamativo en la cadena pública (ARD) que en la comercial (RTL). Aunque Alemania no está implicada en la intervención armada y sí lo está en el debate que se desarrolla en el entorno de la ONU, no deja de ser significativo que el tiempo destinado a los encuentros políticos durante el año 2003 sea cinco veces superior al de los hechos violentos de Irak y durante 2004 lo supere en casi un tercio, a pesar de sucesos tan graves como el asesinato de rehenes norteamericanos capturados por la resistencia iraquí. La emisora privada comparte esta tendencia, pero es más moderada en el reparto de las prioridades y sigue una estrategia diferente: en su conjunto, el tiempo destinado a las declaraciones políticas en Nueva York es superior a los incidentes de Irak, pero el número de noticias distintas sobre el conflicto iraquí es mayor. En cualquier caso, la visibilidad del debate político prevalece sobre la del conflicto en ambas emisoras.

Como es sabido, Alemania se negó a intervenir en la guerra de Irak, condenó el uso de la fuerza y antepuso la autoridad de las Naciones Unidas a la de la Administración norteamericana. Tiene explicación, por tanto, que preste mayor atención a las consecuencias que esa postura pueda tener en sus relaciones internacionales que a la contienda en sí. Por esa misma razón, y de acuerdo con otros intereses de la política exterior alemana, se entiende la amplia información del encuentro entre Bush y Schröeder - que supone la reconciliación con un aliado tradicional de Alemania-, el seguimiento de la campaña electoral estadounidense - por cuanto el resultado pueda influir en esas relaciones-, y el reencuentro entre Bush y Putin, que rompe el siempre temido eje franco-ruso.

En relación con el tratamiento de la información, y como un aspecto más que manifiesta la prioridad concedida a ciertos temas, resulta significativo en ambas cadenas de televisión alemana la ausencia de testimonios directos en las noticias relativas a Irak. $\mathrm{Si}$ bien las declaraciones en las $\mathrm{Na}$ - 
ciones Unidas y los encuentros de Bush con políticos europeos se reproducen con cortes de voz de los protagonistas, los incidentes del conflicto iraquí solo cuentan con el respaldo del relato en off del periodista y apenas recurren a fuentes locales o internacionales que están sobre el terreno. Este comportamiento se mantiene incluso en la cobertura de la captura y asesinato de los rehenes, cuando otras emisoras europeas difunden en directo el vídeo de los secuestrados suplicando por su liberación.

La presencia excesiva del periodista no impide la neutralidad con la que se transmite la información de los sucesos de la posguerra. Los corresponsales no toman parte en la contienda: se limitan a describir la situación, facilitan datos numéricos $\mathrm{y}$ estadísticas, exponen los motivos que explican -sin justificar- la reacción violenta de ambos bandos y apenas utilizan adjetivos que califiquen las diferentes acciones.

Las críticas a Estados Unidos se recogen principalmente en la cobertura de las sesiones de la Asamblea General de la ONU, donde la objetividad del periodista queda limitada por otros desequilibrios. Las noticias suelen comenzar con las declaraciones del presidente Bush, pero posteriormente son matizadas por las intervenciones de Kofi Annan -especialmente duras-, o por la de algún otro político contrario a la intervención en Irak. El tiempo concedido al presidente norteamerica- no es siempre inferior al que tienen sus opositores y los argumentos contrarios tienen más contundencia: la guerra es "más cara y más larga" de lo que Bush esperaba (ARD, 23 de setiembre del 2003); "se juega su supervivencia política" (RTL, 23 de setiembre del 2003); "los ricos manipulan para conseguir riqueza y poder... y hacen mal uso del derecho a luchar contra el terrorismo" (ARD, 21 de setiembre del 2003); "hay más terroristas ahora que antes de la guerra" (ARD, 23 de setiembre del 2004); "la guerra ha puesto en riesgo la función de la justicia, uno de los pilares de la democracia que se pretende instaurar" (RTL, 21 de setiembre del 2004). En el 2003, las críticas a Bush las protagoniza Annan; en el 2004 lo hace Kerry.

A pesar de no dar voz a los ciudadanos iraquíes, ellos son los protagonistas de este periodo de posguerra. Coherentes con el espíritu antibélico que caracteriza a la sociedad alemana, y $\sin$ recurrir a un sensacionalismo extremo, ambas emisoras ponen el acento en el sufrimiento que se inflige a la población civil. Evitan la narración de las operaciones militares y prefieren recoger escenas de individuos concretos, niños y adultos, heridos gravemente o llorando la muerte de un familiar, entierros en poblaciones o barrios pequeños, o los daños causados en los bienes materiales de una población que evidentemente carece de los recursos más básicos. Incluso la noticia del asesinato de los rehenes norteamerica- 
nos está precedida de imágenes de padecimientos de ciudadanos iraquíes. Sin embargo, conviene destacar que mientras la ARD emite las noticias de carácter diplomático como diferentes de las que proceden de Irak, la emisora comercial (RTL) mezcla imágenes y sucesos de una realidad y otra en la misma pieza, subrayando la estrecha conexión que existe entre el conflicto y la negociación que se desarrolla en Occidente.

En la emisora pública, la postura alemana se expone con claridad y coherencia. Aunque se celebra el acercamiento con Estados Unidos, refleja las diferencias todavía existentes: junto al deseo de contribuir al restablecimiento de la paz en Irak, se lamenta de que los plazos para la independencia del país fijados por la Administración Bush no sean más cortos. La oposición de Ángela Merkel, más partidaria de la cooperación militar en las labores humanitarias, solo aparece una vez.

La crítica a Estados Unidos no se realiza abiertamente, sino que se articula a través de la defensa de dos principios: en primer lugar, la autoridad máxima en el ámbito internacional corresponde a las Naciones Unidas ("solo las Naciones Unidas pueden garantizar la legitimidad de una intervención y garantizar la transición a un gobierno democrático" (ARD, 24 de setiembre del 2003); en segundo lugar, la inestabilidad en Irak demuestra que la intervención internacional no es eficaz. El antiamericanismo, por tanto, se limita a una falta de acuerdo en los principios que deben garantizar la seguridad y el orden internacional: ni afecta al conjunto de la nación estadounidense, a la que apenas se alude, ni se hace extensible a la persona y política de Bush.

El análisis cualitativo permite también deducir que las fracturas que la guerra de Irak produce en el entorno europeo no se reflejan en las coberturas de las emisoras seleccionadas. $\mathrm{Si}$ bien recogen con fidelidad la posición del gobierno alemán, la crítica a Estados Unidos es velada y no hacen referencia a la coincidencia o divergencia de Alemania en relación con otros países miembros de la Unión Europea. La escasa aparición de la oposición política impide que se manifieste una fractura ideológica, que, por otra parte, tampoco existe: aunque Merkel sea más partidaria de mantener unas buenas relaciones con Washington, participa del pacifismo tradicional alemán.

Por último, y coincidiendo con la tesis de Lehman, ${ }^{51}$ se puede concluir que la imagen estadounidense en la televisión alemana manifiesta la habilidad de Schröeder para crear un consenso nacional. Es preciso añadir que

51 LEHMANN, Ingrid. Op. cit. 
la opinión pública alemana es tradicionalmente pacifista, independientemente de la posición del gobierno de turno.

\section{España: Un cambio de perspectiva}

La muestra seleccionada de los dos años consecutivos sobre la cobertura de la guerra de Irak en España permite ver una evolución de gran interés. Mientras que en el 2003 el Gobierno estaba presidido por José María Aznar, con una política decidida de apoyo a Estados Unidos, en septiembre del 2004 gobierna el socialista José Luis Rodríguez Zapatero, cuya gestión comenzó precisamente con la retirada de las tropas españolas de Irak. Este cambio en la política interior resulta fundamental para entender el contexto en el que trabajan los medios, los intereses y los argumentos que se emplean y también para entender las diferencias entre la cadena pública, en última instancia dependiente del Gobierno, y la privada. Por este motivo, en el caso de España haremos el análisis diferenciando los dos años examinados.

En el primer periodo de muestra, la guerra de Irak es noticia de primer nivel siempre, excepto un día de la semana en el que no hay noticias al respecto. En el resto de la semana, Irak es el tema que abre los informativos o se coloca en el segundo lugar tras una noticia nacional. La cadena pública TVE incide en las discusiones diplomáticas sobre la guerra y otorga protagonismo a Bush, Aznar, Putin, Chirac, Schröeder y Anam por este orden. Nueva York es el lugar desde el que se emiten las noticias y no tanto Bagdad. Por lo tanto, hay una prioridad por las relaciones políticas sobre las consecuencias que tiene la guerra sobre el terreno. Cuando aparece Irak, se comenta además que "todavía" no se han encontrado armas de destrucción masiva, incidiendo en que las conclusiones de los observadores son aún provisionales. También se recogen voces favorables a la "intervención militar", como la del nuevo secretario general de la OTAN.

La perspectiva nacional sobre la guerra se plantea en tres escenarios. En primer lugar, son noticia las manifestaciones celebradas en distintas ciudades españolas contra la guerra. Por otro lado, también la visita del ministro de Defensa a las tropas felicitándolas por la "misión histórica" que están realizando.

Finalmente, y quizás lo más relevante, en distintas ocasiones se subraya el vínculo del terrorismo con la guerra en Irak. Se habla de "solidaridad en la lucha contra el terrorismo", "lucha contra el terrorismo avalada por la ONU", o se recoge una cita de Aznar comentando que los problemas en Irak se deben "al terrorismo y no a la resistencia popular". Además, se habla en Naciones Unidas de las víctimas del terrorismo y de su reconocimiento. 
La cadena privada Tele 5, en el mismo periodo, presenta una cobertura diferente. Aunque también es la primera noticia y siempre tiene presencia en el informativo, el enfoque presenta al Gobierno español plegado a los dictados de Bush. Como ejemplo, un titular del primer día analizado: "Aznar estrena un avión nuevo para ir a EEUU donde se reunirá con Bush". Se recoge también la buena sintonía entre los dos mandatarios: "el presidente norteamericano ha dicho sobre Aznar que es un líder fuerte, de convicciones".

Otra gran diferencia es el protagonismo que adquiere el corresponsal de la cadena en Irak. Por lo tanto, se emiten más noticias desde los lugares del combate. Además, desde el estudio de los informativos en Madrid se establecen diálogos con el reportero; la conductora del programa, por ejemplo, le pregunta un día por la moral de los soldados norteamericanos, a lo que el corresponsal responde retratándolos como nerviosos y tensos; o por ejemplo, explica que la ceremonia de cesión de Nayaf a las tropas españolas ha sido "una ceremonia breve, sobria, muy a la norteamericana, sin grandes celebraciones".

Sobre las armas de destrucción masiva se es más contundente: no hay rastro. "Los promotores de la guerra no parecen temblar ante el nuevo informe de expertos que dice que no hay rastro de armas de destrucción masiva en Irak, el gran argumento que utilizaron para atacar el país". La conexión con el terrorismo, cuando se hace, siempre aparece en boca de Aznar: "cada uno de los habitantes de nuestro planeta somos víctimas del terrorismo".

Por último, se habla también de las repercusiones de Irak en Estados Unidos, políticas y económicas, y de la perdida de popularidad de Bush. En esta clave, se justifican y se explican las decisiones que toma el gobierno norteamericano en Irak: "llegan las elecciones y sabe que si quiere obtener el apoyo de otros países...". Al año siguiente se aprecia un cambio notable en la cobertura del tema. Si el terrorismo era uno de los argumentos fundamentales en el 2003 en TVE, en el 2004 desaparece totalmente y pasa a tener el máximo protagonismo la violencia que se ha desatado en Irak. En este momento, además, las diferencias entre la televisión pública y la privada tienden a desaparecer.

Todos los días, excepto uno, Irak es tema de los informativos y también se trata de una noticia de primer orden. Se aprecia una cantidad mayor de informaciones emitidas desde Irak, aunque también Naciones Unidas es noticia, por el discurso de Zapatero. Los noticieros en el 2004 empiezan con "otro día trágico en Irak", "sigue la incertidumbre", y los secuestros de los extranjeros ocupan gran cantidad de informaciones; por eso también se recogen reacciones desde Reino Unido o Italia al respecto. 
El protagonismo de las informaciones pasan a tenerlo estas víctimas de la guerra. Los políticos están en un segundo plano, aunque Zapatero, Bush y Annan, en este orden, acaparan el contenido informativo. Los discursos de Bush en Naciones Unidas se explican también en clave electoral, y en las dos emisoras hay noticias sobre la política interior norteamericana.

Otra cuestión interesante es el estilo informativo de TVE, que se parece más al de la cadena privada, puesto que los corresponsales pasan a tener más relevancia y también se realizan diálogos con los periodistas del plató. Por ejemplo, se le pregunta al corresponsal de Nueva York: ¿qué ha dicho de nuevo Bush? Y el corresponsal explica que su discurso se entiende por las elecciones que están a la vuelta de la esquina. $\mathrm{O}$ ¿sabemos qué le ha parecido al presidente Zapatero el discurso de Bush? "Sí, comparte el proyecto de extender la democracia, pero no la guerra de Irak".

Por lo tanto, los cambios en el Gobierno parecen influir, sin lugar a dudas, en el cambio de la cobertura que realiza la cadena pública. Esta se caracteriza en una primera etapa por su argumentación en torno al terrorismo y por la prioridad de las acciones políticas sobre el conflicto. El tono periodístico que se utiliza es distante y $\sin$ apenas intervenciones directas de los protagonistas de las noticias. Al año siguiente, su cobertura se asimila más a la de la cadena privada, en la que se da mayor información de las víctimas del conflicto y de los problemas en Irak, y se personalizan las críticas (Aznar y Bush). Además, los periodistas parecen mantener una postura más comprometida, con un estilo más directo.

\section{Conclusiones}

El reciente antiamericanismo europeo es causado por las decisiones de la Administración Bush y no por una animosidad generalizada contra Estados Unidos, pero ha hecho resurgir prejuicios anteriores que han permanecido latentes en las opiniones públicas europeas. La historia política de cada nación incide de manera decisiva en la forma de entender el orden internacional y, en particular, en la opinión sobre los principios del war on terrorism de Estados Unidos, el pacifismo alemán y el colaboracionismo inglés. El antiamericanismo se expresa en el debate sobre los principios que deben regir el orden internacional: unilateralismo versus multilateralismo y militarismo versus diplomacia.

En relación con la guerra de Irak, en primer lugar se debe afirmar que la televisión europea concede tanta importancia a las relaciones diplomáticas como a los acontecimientos violentos del conflicto. Este equilibrio en la cobertura no se explica solo por el interés mediático que despierta la apertura de la Asamblea General de las Naciones Unidas, ya que las inci- 
dencias que tuvieron lugar esos días en Irak (explosión de un coche bomba en la sede de las Naciones Unidas, el 2003, y el secuestro y asesinato de ciudadanos europeos el 2004) son igualmente relevantes. La duración concedida a las diferentes noticias demuestra que los gobiernos europeos, también los que participan con tropas en el conflicto, se juegan más en las negociaciones políticas que en las acciones militares.

En segundo lugar, se aprecia que la cobertura de las noticias relacionadas con Irak se convierte en ocasión para emitir juicios sobre el orden internacional y para reflejar una visión particular sobre la política exterior de la Administración republicana y sobre el Presidente.

En tercer lugar, cabe destacar una diferencia entre el comportamiento de los medios europeos y estadounidenses. Si bien los estudios sobre el comportamiento de los medios norteamericanos afirman una cierta tendencia a la dependencia de las fuentes oficiales, la televisión europea recoge mayor pluralidad de fuentes y de voces en sus narraciones. En cualquier caso, es necesario precisar que los gobiernos europeos gozan siempre de un protagonismo especial.

En relación con la imagen de Estados Unidos en Europa, la primera conclusión es que se identifica con la imagen de su presidente. Es prácticamente la única fuente norteamericana con declaraciones directas en el periodo analizado y monopoliza también las imágenes de representantes de ese país, con excepción de algunas apariciones de soldados anónimos desplazados a Irak. El contenido esencial de las informaciones son los discursos del presidente Bush y de sus visitas diplomáticas y no tanto de las acciones del ejército estadounidense en la zona del conflicto.

Por otra parte, la disposición de los contenidos favorece la imagen de Bush como líder internacional. Las noticias abren con una acción o declaración del Presidente ante las que reaccionan los demás actores políticos. Independientemente de que la visión sea positiva o negativa, la percepción es que Estados Unidos genera $\mathrm{y}$ establece los términos del debate político.

Incluso las críticas a la política de Washington se realizan, en primer lugar, a través de las declaraciones de autoridades que se oponen a la interpretación de Bush y que se emiten inmediatamente después de las intervenciones del Presidente, matizando y cuestionando las afirmaciones realizadas por él.

Los principales aspectos que se cuestionan y que se utilizan para evaluar la credibilidad de la política americana son:

- Eficacia de la intervención militar como medida para prevenir ataques contra la seguridad interna- 
cional. En este sentido, la cobertura de las acciones violentas en Irak suelen finalizar con el interrogante sobre la operatividad de las tropas internacionales.

- La entidad real de la amenaza que presenta Irak a la seguridad internacional y, en conexión con ello, el debate sobre la veracidad de las pruebas que indujeron a la invasión militar.

- La aceptación de la acción militar norteamericana por los ciudadanos iraquíes.

Las fracturas que el debate sobre la guerra de Irak provoca en el entorno europeo se perciben también en los diferentes enfoques de las emisoras. La televisión de los países que se han opuesto a la guerra (Francia y Alemania) recogen las diferencias entre los distintos países europeos, mostrando la fractura en el seno de la Unión Europea, pero apenas reflejan la oposición política interna -con una ausencia significativa de representantes partidarios de la intervención americana-. La fractura entre gobierno y ciudadanía es inexistente y apenas está presente en los informativos; por el contrario, muestran con más frecuencia las manifestaciones de rechazo de la política estadounidense.

La televisión de Gran Bretaña y de España reflejan la fractura ideológica -enfrentamiento entre las diversas fuerzas políticas de la país- y la fractura gobierno-ciudadanía, y apenas prestan atención a las reacciones en otras naciones europeas. La razón es el importante debate interno que generan las dudas sobre la existencia de armas de destrucción masiva en Irak, el secuestro de civiles extranjeros por los rebeldes iraquíes y la ineficacia de la intervención militar. La credibilidad de Blair y Aznar está en entredicho.

Estas conclusiones describen el clima anterior a la positiva expectación que actualmente ha generado Barack Obama. Pero pervive como una amenaza o como una experiencia que debería ser tenida en cuenta por la nueva Administración estadounidense, por cuanto no responde solo a unas circunstancias políticas. Tiene un importante arraigo en enfoques culturales y volverá a aparecer si Estados Unidos no modifica sustancialmente su forma de ejercer el liderazgo internacional.

\section{Bibliografía}

ADAY, S.; LIVINGSTON, S. y M. HEBERT. “Embedding the truth: A cross-cultural analysis of objectivity and television coverage of the Iraq war". Press/Politics, 10(1) 2005.

ADAY, Sean. "The real war will never get on television an analysis of casualty imagery in american television coverage of the Iraq war", en SEIB, P. Media and conflict in the twenty-first century. Nueva York: Palgrave Macmillan, 2005. 
APPLEBAUM, Anne. "In search of pro americanism". Foreign Policy. Julio-agosto, 2005.

BALIS, Christina V. y Simon SERFATY. "Visions of America and Europe: September 11, Iraq, and transatlantic relations". Significant Issues Series. Vol. 26, núm. 3. Washington, D.C.: Center for Strategic Studies, 2004.

BARABAS, Jason. "Certitude: Uncertain knowledge and message clarity in mediated deliberation". American Political Science Association Conference on International Communication and Conflict at Georgetown University and George Washington University, Washington, D.C. Agosto del 2005.

BENNETT, W. L. y S. LIVINGSTON. "Gatekeeping, indexing, and liveevent news: Is technology altering the construction of news?". Political Communication 20, 2003.

BENNETT, W. L. y D. PALETZ. Taken by storm. The media, public opinion and US foreign policy in the Gulf war. Chicago: The University of Chicago Press, 1994.

Cardiff School of Journalism, Media and Cultural Studies. "The role of embedded reporting during the 2003 Iraq war". Report Commissioned by the British Broadcasting Company, 2003.

COTTLE, Simon. "Mediatizing the global war on terror", en KAVOO-
RI, A. y T. FRALEY (eds.). Mediated terrorism: Readings in theory. Boulder, CO: Rowman \& Littlefields, 2006.

DEER, Patrick. "The dogs of war: Myths of british anti-americanism", en ROSS, Andrew y Kristi ROSS. Anti-americanism. Nueva York: Nueva York University Press, 2004.

DRUCKMAN, James N. "Media matter: How newspapers and television news cover campaigns and influence voters. Political Communication 22, 2005.

EUROPEAN COMMISSION. Standard Eurobarometer 65, Executive Summary, 2006.

FREEDMAN, Lawrence. "War in Iraq: selling the truth". Survival. Vol. 46, núm. 2, 2004.

GAMSON, W. A. "News as framing". American Behavioral Scientist 33 (2), 1989.

GARTON ASH, Timothy. "Anti-europeism in America". New York Review of Books, 13 de febrero del 2003.

HAMMOND, Philip. "Postmodern war in Iraq", en NIKOLAEV, A. y E. HAKANEN (eds.). Leading to the 2003 Iraq war: the global media debate. Nueva York: Palgrave Macmillan, 2006.

HARRIS, Richard Jackson y Joseph Andrew KARAFA. "A cultivation 
theory perspective of world wide national impressions of the United States", en KAMALIPOUR, Y. R. Images of the US around the world. A multicultural perspective. Nueva York: State University of NY Press, 1999.

HAUMANN, Wilhelm y Thomas PETERSON. "German public opinion on the Iraq conflict: A passing crisis with the USA or a lasting departure?". International Journal of Public Opinion Research 16, 2004.

HERTOGHE, Alain. La guerre à outrances. París: Calmann-Lévy, 2003.

HILL, Christopher. "Dilemmas of a semi-insider: Blairite britain and the United States", en BALIS, Christina V. y Simon SERFATY. Visions of America and Europe: September 11, Iraq, and transatlantic relations. Significant Issues Series. Vol. 26, núm. 3. Washington, D.C.: Center for Strategic Studies, 2004.

IYENGAR, S. y A. SIMON. "News coverage of the Gulf crisis and public opinion". Communication Research, 20 (3), 1997.

JOHNSON-CARTEE, Karen S. News Narratives and News Framing: Constructing Political Reality. Lanham, MD: Rowman \& Littelefield Publishers, 2005.

KAGAN, Robert. Of Paradise and Power: America and Europe in the New world order. Nueva York: Alfred A. Knopf, 2003.
KAMALIPOUR, Y. R. Images of the US around the world. A multicultural perspective. Nueva York: State University of NY Press, 1999.

KATOVSKY, Bill y Timothy CARLSON. Embedded: The media at war in Iraq. Guilford, CT: The Lyons Press, 2003.

KELLNER, D. "September 11, the media, and war fever". Television $\mathcal{E}$ New Media, 3 (2), 2002.

KULL, Steven; RAMSAY, Clay y Evan LEWIS. "Misperceptions, the media and the Iraq war". Political Science Quarterly. Vol. 118(4), 2003.

LA PORTE, M. T. “Efectos de los medios en las controversias internacionales", en RODRÍGUEZ, R., y T. SÁDABA (eds.). Periodistas ante conflictos. Pamplona: Eunsa, 1999.

LA PORTE, T. et al. "Globalization of the media industry and possible threats to cultural diversity" [en línea]. <http:// www.europarl.eu. int/stoa/publi/pdf/summaries/0013-01sum_es. pdf>.

LEHMANN, I. "Exploring the transatlantic media divide over Iraq: How and why U.S. and German media differed in reporting on UN weapons inspections in Iraq, 20022003". The Harvard International Journal of Press/Politics 10, 2005.

LEWIS, Justin. “Television, public opinion, and the war in Iraq: The case of Britain". International Journal of Public Opinion 16, 2004. 
MEUNIER, Sophie. "Anti-Americanisms in France". European Studies Newsletter Council for European Studies. Vol. XXXIV, núms. 3-4. Enero del 2005.

MILLER, Toby. "Anti-americanism and popular culture". Anti-Americanism Working Paper. Central European University, 2005.

MOWLANA, H.; GERBNER, G. y H. SCHILLER (eds.). Triumph of the image: The media's war in the Gulf. A global perspective. Boulder, CO: Westview Press, 1992.

NATIONAL ARTS JOURNALISM PROGRAM. "Cultural diplomacy amid global tension". Conferencia. Center for Arts \& Culture, 2003.

NIMMO, Dan y James E. COMBS. Mediated political realities. Nueva York, NY: Longman, 1983.

NOLAN, Mary. "Anti-americanization in Germany", en ROSS, Andrew y Kristi ROSS. Anti-americanism. Nueva York: NY University Press, 2004.

OBAJTEK-KIRKWOOD, Anne-Marie. "Le Monde on a 'likely' Iraq war", en NIKOLAEV, Alexander G. y Ernest A. HAKANEN. Leading to the 2003 Iraq war: the global media debate. Nueva York: Palgrave Macmillan, 2006.

PARMENTIER, G. The United States Today. París: Odile Jacob, 2004.

PETER, J.; LAUF, Edmund y Holli SEMETKO. "Television coverage of the 1999 European Parliamentary elections". Political Communication 21, 2004.

Pew Research Center for the People \& the Press. Views of a changing world june 2003, 2003.

Pew Research Center for the People \& the Press, 2006.

PFAU, M. et al. “Embedding journalists in military combat units: Impact on newspaper story frames and tone". Journalism and Mass Communication Quarterly 81, 2004.

PILGER, John. "We see too much. We know too much. That's our best defense". The Independent. 6 de abril del 2003.

RAVI, Narasimhan. “Looking beyond flawed journalism: How national interest, patriotism, and cultural values shaped the coverage of the Iraq war". The Harvard Journal of Press Politics, Vol. 10, núm. 1, 2005.

REVEL, Jean François. L'obsession antiaméricaine: Son fonctionnement, ses causes, ses inconséquences. París: Plon, 2002.

RYAN, Michael. "Framing the war against terrorism: U.S. newspaper editorials and military action in Afghanistan". The International Communication Gazette 66, 2004.

SADABA, T. y M. T. LA PORTE. “Mediated terrorism in comparative perspective: Spanish Press Coverage of $9 / 11$ vs. Coverage of basque terrorism", en KAVOORI, A. y T. 
FRALEY (eds.). Mediated terrorism: Readings in theory. Boulder, CO: Rowman \& Littlefields, 2005.

SCHOU, S. "Postwar americanization and the revitalization of european culture", en SKOVMAND, M. y K. SCHRODER (eds.). Media cultures: Reappraising trasnational media. Londres: Routledge, 1993.

SERFATY, Simon. La France vue d'Amérique: Reflexions sur la francophobie á Washington. París: IFRI, 2002.

STEVENS, Daniel et al. "Local news coverage in a social capital: Election 2000 on Minnesota's local news station". Political Communication 23, 2006.
The Economist. "Axis of feeble". 13 de mayo del 2006.

TUMBER, Howard y Jerry PALMER. Media at war. The Iraqi crisis. California: SAGE Publications Ltd, 2004.

WASBURN, P. C. The social construction of international news. We're talking about them, they're talking about us. Nueva York: Praeger, 2002.

WEIGEL, George. Política sin Dios. Nueva York: Basic Books, 2005.

WOLDT. R. y J. DRIES. Perspectives of public service television in Europe. Düsseldorf: Europäisches Medieninstitut, 1998. 